Research Article

\title{
Hybrid Effect of Wollastonite Fiber and Carbon Fiber on the Mechanical Properties of Oil Well Cement Pastes
}

\author{
Jianglin Zhu $\mathbb{D}^{1,2}$ Jiangxiong Wei, ${ }^{1}$ Qijun Yu, ${ }^{1}$ Mingbiao $\mathrm{Xu}^{3}$ and Yuwei Luo ${ }^{4}$ \\ ${ }^{1}$ School of Materials Science and Engineering, South China University of Technology, Guangzhou 510000, China \\ ${ }^{2}$ Southern Marine Science and Engineering Guangdong Laboratory (Zhanjiang), Zhanjiang 524000, China \\ ${ }^{3}$ School of Petroleum Engineering, Yangtze University, Wuhan 430000, China \\ ${ }^{4}$ China Oilfield Services Limited Oilfield Chemicals Division, Beijing 100000, China \\ Correspondence should be addressed to Jianglin Zhu; jianglinzhu123@163.com
}

Received 30 April 2020; Revised 6 October 2020; Accepted 20 October 2020; Published 17 November 2020

Academic Editor: Rishi Gupta

Copyright ( $) 2020$ Jianglin Zhu et al. This is an open access article distributed under the Creative Commons Attribution License, which permits unrestricted use, distribution, and reproduction in any medium, provided the original work is properly cited.

\begin{abstract}
Oil well cement is a type of natural brittle material that cannot be used directly in cementing operations. Fiber is a type of material that can effectively improve the strength and toughness of cement stone, and hybrid fiber materials can more effectively improve the performance of a cement sample. To overcome the natural defects of oil well cement, the new mineral fiber, i.e., wollastonite fiber, and common carbon fiber were used in oil well cement, and the micromorphology, mechanical properties, and stress-strain behavior of the cement were evaluated. The experimental results show that carbon fiber and wollastonite fiber are randomly distributed in the cement paste. The mechanical properties of the cement paste are improved by bridging and pulling out. The compressive strength, flexural strength, and impact strength of cement stone containing only carbon fiber or wollastonite fiber are higher than those of the pure cement, but too many fibers are not conducive to the development of mechanical properties. A mixture of $0.3 \%$ carbon fiber with $6 \%$ wollastonite fiber in oil well cement slurry results in a greater increase in compressive strength, flexural strength, and impact strength. In addition, compared with blank cement stone, the strain of the mixed cement stone increases substantially, and the elastic modulus decreases by $37.8 \%$. The experimental results supply technical support for the design of a high-performance cement slurry system.
\end{abstract}

\section{Introduction}

The cementing operation injects cement slurry into the casing and formation annulus and forms a cement sheath after the cement slurry solidifies to effectively seal the layers and support and protect the casing [1]. After cementing, the cement sheath is subjected to impact force via various operations in the subsequent pressure testing, perforation, fracturing, and other construction processes, which require cement stone with good mechanical properties. Oil well cement is a type of brittle material that has poor resistance to external force [2]. Addition of reinforcement and toughening materials to cement can overcome the defects of oil well cement.

Currently, the main fibers used in oil well cement include polymer fibers and mineral fibers. Ahmed et al. [3] evaluated the function of polypropylene fiber and found that the effect of polypropylene fiber on the density, rheology, and free liquid of cement slurry can be ignored, the compressive strength of cement stone is improved, and the permeability of cement stone is reduced. Iremonger et al. [4] applied reinforced fiber as a cement additive in a thermal recovery well. The reinforced fiber had a certain stabilizing effect on the compressive strength and Young's modulus of the cement sample under high temperature. Liu et al. [5] studied the effect of cellulose fiber on the properties of low-density cement paste. Mechanical properties such as the tensile strength and flexural strength of cement stone and the elastic deformation ability of cement stone were improved. Research results from $\mathrm{Bu}$ et al. [6] and $\mathrm{Li}$ et al. [7] showed that carbon fiber can effectively improve the mechanical properties and deformation ability of cement paste. These studies 
demonstrated that the polymer fiber can improve the mechanical properties of the cement sheath, including compressive strength, impact strength, and crack phenomena during perforation.

In addition, Li et al. [8] and $\mathrm{Li}$ and Zhuang [9] studied the influence of brucite fiber on the performance of oil well cement. The results showed that the splitting tensile strength, compressive strength, and flexural strength of brucite fiber cement stone are much higher than those of pure cement stone, and the elastic modulus is decreased. Paivaa et al. [10], Jiang et al. [11], and Rambo et al. [12] showed that basalt fiber can improve the tensile strength, flexural strength, and other mechanical properties of cement paste. Kurata and Umemoto [13] studied the effect of aluminum borate whiskers on the performance improvement of polycarboxylic cement-based materials. The tensile strength of cement paste containing aluminum borate whiskers is three times that of the sample without whiskers, and the compressive strength increases. These studies demonstrate that materials with both micropowder and fiber properties show improved mechanical properties in cement-based materials.

Wollastonite fiber is a new type of mineral fiber that has not previously been used in oil well cement. This material is a chain-like metasilicate mineral with a special crystal structure and has the characteristics of mineral powder and fiber. Carbon fiber is one of the most commonly used strengthening and toughening materials in cement slurry. Certain reports have studied the hybrid effect of polymer fiber and inorganic mineral fiber and found that hybrid use of the two fibers can fully leverage the role of the fiber and more effectively improve the performance of cement stone [14]. Therefore, this work studies the effect of wollastonite fiber and carbon fiber in oil well cement and mixes them to study the mechanical properties of the hybrid fiber cement, thus supplying technical support for the design of a high-performance cementing slurry system.

\section{Experimental Materials and Methods}

2.1. Materials. API standard class G oil well cement was purchased from Gezhouba Special Cement Co., Ltd., China. The chemical composition of oil well cement is presented in Table 1. Wollastonite fiber and carbon fiber were commercially obtained from the market. The properties of wollastonite fiber are shown in Tables 2 and 3. The properties of carbon fiber are presented in Table 4. Filtrate reducer, enhancer, retarder, and dispersant were also sourced on the market from professional companies. These four materials are necessary additives for cement slurry and are used to reduce the water loss, improve the compressive strength, adjust the thickening time, and improve the fluidity of the cement slurry.

\subsection{Preparation of Cement Slurry}

2.2.1. Application Method of Carbon Fiber. Selected studies have shown that carbon fiber is easily agglomerated in the process of application and is not evenly dispersed in the
TABle 1: Chemical composition of oil well cement.

\begin{tabular}{lcccccc}
\hline $\begin{array}{l}\mathrm{CaO} \\
(\%)\end{array}$ & $\begin{array}{c}\mathrm{SiO}_{2} \\
(\%)\end{array}$ & $\begin{array}{c}\mathrm{Al}_{2} \mathrm{O}_{3} \\
(\%)\end{array}$ & $\begin{array}{c}\mathrm{Fe}_{2} \mathrm{O}_{3} \\
(\%)\end{array}$ & $\begin{array}{c}\mathrm{MgO} \\
(\%)\end{array}$ & $\begin{array}{c}\mathrm{SO}_{3} \\
(\%)\end{array}$ & $\begin{array}{c}\mathrm{Na}_{2} \mathrm{O}+\mathrm{K}_{2} \mathrm{O} \\
(\%)\end{array}$ \\
\hline 64.6 & 22.2 & 3.7 & 4.8 & 1.3 & 2.9 & 0.5 \\
\hline
\end{tabular}

TABLE 2: Basic properties of wollastonite fiber.

\begin{tabular}{lccccc}
\hline $\begin{array}{l}\text { Average } \\
\text { grain size } \\
(\mu \mathrm{m})\end{array}$ & $\begin{array}{c}\text { Aspect } \\
\text { ratio }\end{array}$ & $\begin{array}{c}\text { Density } \\
\left(\mathrm{g} / \mathrm{cm}^{3}\right)\end{array}$ & $\begin{array}{c}\text { Ignition } \\
\text { loss }(\%)\end{array}$ & $\begin{array}{c}\text { Melting } \\
\text { point } \\
\left({ }^{\circ} \mathrm{C}\right)\end{array}$ & $\begin{array}{c}\text { Mohs } \\
\text { hardness }\end{array}$ \\
\hline 48 & $>12$ & 2.8 & 1.8 & 1540 & $4.5-5.5$ \\
\hline
\end{tabular}

cement slurry $[15,16]$. Therefore, carbon fiber should be predispersed in the process of application. After weighing the prepared aqueous solution, carbon fiber of a specified quality is uniformly added to the aqueous solution, and the carbon fiber dispersion is formed after stirring via a corrugated agitator for approximately $30 \mathrm{~s}$. The carbon fiber dispersion solution is used as the slurry preparation solution to prepare the cement slurry.

2.2.2. Preparation of Cement Slurry. The cement slurries are prepared according to Table 5. The cement, filtrate reducer, enhancer, and dispersant of specified quality are weighed as dry powder, and water and retardant of a specified quality are weighed as mixing water. The use of carbon fiber refers to the steps described above, and wollastonite fiber is used as a component of dry powder. The materials are poured with the mixed water into the mixing cup and stirred at $4000 \pm 200 \mathrm{r} / \mathrm{min}$ with a constant speed mixer (TG-3060A, Shenyang Taige Petroleum Instrument \& Equipment Co., Ltd.), and the dry powder is added evenly within $15 \mathrm{~s}$. After all of the mixed dry powder is poured into the mixing water, the mixing cup is covered, and stirring is continued for $35 \mathrm{~s} \pm 1 \mathrm{~s}$. In this manner, the cement slurry system is prepared.

2.3. Mechanical Properties Test. After the cement slurry is prepared, it is poured into the compressive strength, flexural strength, and impact strength test molds and cured in a water bath at $80^{\circ} \mathrm{C}$ and atmospheric pressure. The sample sizes of the compressive strength and flexural strength test samples are $50.8 \mathrm{~mm} \times 50.8 \mathrm{~mm} \times 50.8 \mathrm{~mm}$ and $40 \mathrm{~mm} \times 40 \mathrm{~mm} \times 160 \mathrm{~mm}$, respectively. The compressive strength and flexural strength of cement stone are tested by a fully automatic flexural and compression testing machine (YAW-300C, Ji'nan Zhongluchang Testing Machine Manufacturing Co., Ltd., China). The compressive strength test uses a constant speed compressive stress of $72 \mathrm{kN} / \mathrm{min}$ according to the Chinese standard GB/T 19139-2012. The flexural strength is tested by the three-point bending method. The sample size for the impact strength test is $10 \mathrm{~mm} \times 15 \mathrm{~mm} \times 120 \mathrm{~mm}$. The impact strength of the cement samples is tested by a pendulum impact tester (XJJY-50, Chengdeshi Shipeng Detection Equipment Co., Ltd., China). 
TABLE 3: Chemical composition of wollastonite fiber.

\begin{tabular}{lccccc}
\hline $\mathrm{SiO}_{2}(\%)$ & $\mathrm{CaO}(\%)$ & $\mathrm{Al}_{2} \mathrm{O}_{3}(\%)$ & $\mathrm{MgO}(\%)$ & $\mathrm{Fe}_{2} \mathrm{O}_{3}(\%)$ & $\mathrm{Others}(\%)$ \\
\hline 51.5 & 42.4 & 2.1 & 0.7 & 0.5 & 2.8 \\
\hline
\end{tabular}

TABLE 4: Basic properties of carbon fiber.

\begin{tabular}{ccccccc}
\hline Length $(\mathrm{mm})$ & Single diameter $(\mu \mathrm{m})$ & Tensile strength $(\mathrm{MPa})$ & Tensile modulus $(\mathrm{GPa})$ & $\begin{array}{c}\text { Density } \\
\left(\mathrm{g} / \mathrm{cm}^{3}\right)\end{array}$ & Elongation (\%) & Carbon content $(\%)$ \\
\hline 1 & 7 & 3530 & 230 & 1.78 & 1.5 & $\geq 96$ \\
\hline
\end{tabular}

TABLE 5: Mix compositions of oil-well cement slurries.

\begin{tabular}{lcccccccc}
\hline $\begin{array}{l}\text { Sample } \\
\text { number }\end{array}$ & $\begin{array}{c}\text { Cement } \\
\text { (wt.\%) }\end{array}$ & $\begin{array}{c}\text { Water } \\
\text { (wt. \%) }\end{array}$ & $\begin{array}{c}\text { Filtrate reducer } \\
\text { (wt. \%) }\end{array}$ & $\begin{array}{c}\text { Enhancer } \\
\text { (wt. \%) }\end{array}$ & $\begin{array}{c}\text { Dispersant } \\
\text { (wt. \%) }\end{array}$ & $\begin{array}{c}\text { Retarder } \\
\text { (wt. \%) }\end{array}$ & $\begin{array}{c}\text { Carbon fiber } \\
\text { (wt. \%) }\end{array}$ & $\begin{array}{c}\text { Wollastonite fiber } \\
\text { (wt. \%) }\end{array}$ \\
\hline P & 100 & 44 & 2 & 1.5 & 0.8 & 0.5 & 0 & 0 \\
C1 & 100 & 44 & 2 & 1.5 & 0.8 & 0.5 & 0.1 & 0 \\
C2 & 100 & 44 & 2 & 1.5 & 0.8 & 0.5 & 0.2 & 0 \\
C3 & 100 & 44 & 2 & 1.5 & 0.8 & 0.5 & 0.3 & 0.4 \\
C4 & 100 & 44 & 2 & 1.5 & 0.8 & 0.5 & 0 & 0 \\
W1 & 100 & 44 & 2 & 1.5 & 0.8 & 0.5 & 0 & 0 \\
W2 & 100 & 44 & 2 & 1.5 & 0.8 & 0.5 & 0 & 0 \\
W3 & 100 & 44 & 2 & 1.5 & 0.8 & 0.5 & 0.5 & 0.3 \\
W4 & 100 & 44 & 2 & 1.5 & 0.8 & 0.5 & 0.5 \\
CW1 & 100 & 44 & 2 & 1.5 & 0.8 & 0.5 & 0.3 & 3 \\
CW2 & 100 & 44 & 2 & 1.5 & 0.8 & 0.5 & 0.5 \\
CW3 & 100 & 44 & 2 & 1.5 & 0.8 & 0.5 & 6 \\
\hline
\end{tabular}

2.4. Test of Stress-Strain Behavior. The test sample was prepared according to the preparation process of cement slurry mechanical property test sample. After 28-day curing, a universal testing machine (HY-20080, Shanghai Hengyi Precision Instrument Co., Ltd., China) was used to test the unconfined stress-strain of cement stone according to the Chinese standard GB/T 50266-2013.

2.5. Fracture Surface Morphology Observation of Cement Sample. The cement paste sample was crushed, and the regular thin section on the middle part was selected to stop hydration treatment. The samples were dried at constant temperature in the oven. After the samples were cooled, they were pasted on the test bench. The samples were observed by the scanning electron microscope (SU 8010, Hitachi).

\section{Results and Discussion}

3.1. Mechanism of Fiber-Reinforced Cement Paste. Fiber is a type of material with a high aspect ratio. The microstructure of the two types of fiber materials was observed via SEM. Figures 1(a) and 1(b) show SEM images of single carbon fiber and wollastonite fiber, respectively. As observed from Figure 1(a), the carbon fiber is longer, the length diameter ratio is larger, and the shape is more regular. The length diameter ratio of the wollastonite fiber is small, and the length is short, as shown in Figure 1(b).

Figure 2 shows SEM images of cement stone with $0.3 \%$ carbon fiber. It can be observed from Figure 2(a) that the distribution of carbon fiber in the cement paste is disorderly and without clusters. Figure 2(b) shows the "pull-out" and "bridging" effect of carbon fiber in the cement paste. Because carbon fiber has a high aspect ratio, when cracks appear in the carbon fiber cement stone specimen, the fiber transmits the tensile stress to the matrix through the cohesive force and mechanical bite force, which limits the expansion of local cracks in the cement specimen. When the development of cracks is inevitable, the fibers in the cracks are stretched, pulled out or broken. At this time, a large amount of energy is consumed, and thus the fracture toughness of cement materials can be greatly improved, and the brittleness of the matrix during the fracture can be significantly reduced [17-19]. In the area where the distribution of carbon fiber is consistent with the direction of crack development, the crack is difficult to deflect and can only continue to expand along the original direction. At this time, the carbon fiber close to the crack tip is not pulled out or broken but forms a similar "bridging" function on both sides of the crack and produces a compressive stress on the crack surface, which offsets the external stress to a certain extent, thus preventing crack growth and enhancing the mechanical properties of the cement paste [20].

Figure 3 shows the fracture morphology of wollastonite fiber cement stone. It can be observed in Figure 3(a) that wollastonite fibers are randomly distributed inside the cement stone and cross-linked with the cement stone matrix. Figure 3(b) shows the structure of carbon fiber interpenetrating with the cement hydration products in the cement matrix. Wollastonite fiber plays a similar role as carbon 


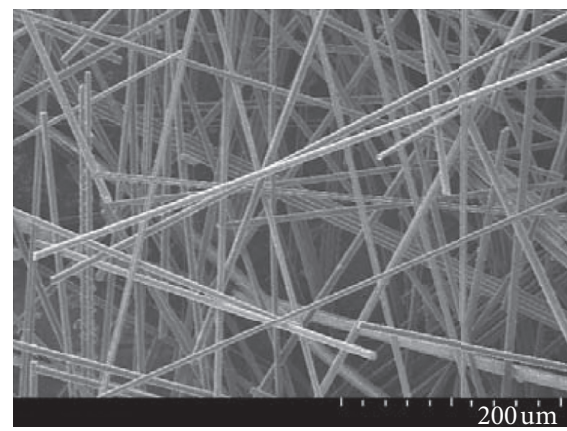

(a)

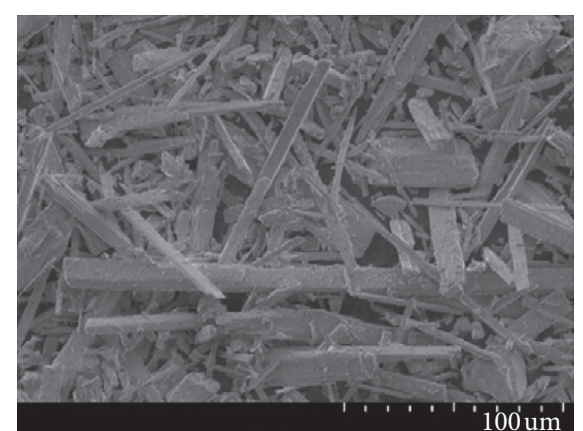

(b)

FIGURE 1: Morphology of single carbon fiber and wollastonite fiber. (a) Carbon fiber. (b) Wollastonite fiber.

fiber in the cement paste. Via the "bridging" and "pulling out" functions, the toughness and strength of the cement paste are improved.

\subsection{Mechanical Properties of Cement Slurry}

3.2.1. Effect of Carbon Fiber on the Mechanical Properties of Cement Paste. The main mechanical properties of the cement slurry include compressive strength, flexural strength, and impact strength. The compressive strength of cement stone represents the ability to maintain the integrity of the cement stone under compressive stress and is the maximum stress of cement stone under the action of a uniform compressive stress on the unit stress contact surface [21]. The flexural strength can be directly used to characterize the ability of the cement sheath to bear external shear and indirectly used to characterize the toughness of cement stone [22]. The impact strength is the energy consumed by the cement specimen after impact fracture, which indicates the ability of the cement stone to withstand impact. The impact strength is a significant index in evaluation of the toughness of cement stone, and its value can directly reflect the toughness and quantitatively characterize the toughening effect of the cement stone [23].

The compressive strength, flexural strength, and impact strength of cement pastes with different amounts of carbon fiber were evaluated under the conditions of temperature curing for $1 \mathrm{~d}, 3 \mathrm{~d}, 7 \mathrm{~d}, 14 \mathrm{~d}$, and $28 \mathrm{~d}$, and the results are presented in Figures 4-6. It can be observed from the figures that with the extension of curing time, the compressive strength, flexural strength, and impact strength of cement stone are increased.

As shown in Figure 4, as the fiber content increases, the compressive strength of the cement paste increases. The compressive strengths of cement paste containing $0.1 \%$, $0.2 \%, 0.3 \%$, and $0.4 \%$ carbon fiber are increased by $8 \%$, $11.25 \%, 17.5 \%$, and $19.75 \%$, respectively, compared with those of pure cement paste. The addition of carbon fiber can improve the compressive strength of cement paste.

The results in Figure 5 show that the flexural strengths of cement paste with different carbon fiber content vary significantly. Carbon fiber can improve the flexural strength of cement paste, but too much carbon fiber has a negative impact on the flexural strength. If the content of carbon fiber is greater than $0.3 \%$, the flexural strength decreases. If the curing time is 1 day, the flexural strengths of cement stone containing $0.1 \%, 0.2 \%, 0.3 \%$, and $0.4 \%$ carbon fiber are $4.7 \%$, $12.7 \%, 25.4 \%$, and $15.9 \%$ higher, respectively, than that of pure cement stone. With the extension of curing time, the flexural strength is increased. When the curing time reaches 28 days, the flexural strength of cement stone containing $0.3 \%$ carbon fiber is the largest and is $30.3 \%$ higher than that of the pure cement stone, reaching $12.9 \mathrm{MPa}$.

Figure 6 shows that carbon fiber can effectively improve the toughness of cement, but excessive carbon fiber is not conducive to the development of impact strength. When the curing time is 1 day, the impact strength of cement stone containing $0.3 \%$ carbon fiber is the largest, reaching $1.8 \mathrm{~kJ} / \mathrm{m}^{2}$. With the increase of curing time, the impact strength increases. When the curing time is 28 days, the flexural strengths of cement stone containing $0.1 \%, 0.2 \%, 0.3 \%$, and $0.4 \%$ carbon fiber are $7.5 \%, 14 \%$, $18.3 \%$, and $12.9 \%$ higher, respectively, than those of pure cement stone. Carbon fiber can effectively improve the impact strength of cement paste.

\subsubsection{Effect of Wollastonite Fiber on the Mechanical Prop-} erties of Cement Slurry. The compressive strength, flexural strength, and impact strength of cement paste with different wollastonite fiber content were tested, and the test results are presented in Figures 7-9. The data in Figure 7 show that the compressive strength of cement stone increases with the extension of curing time. The compressive strength of $8 \%$ wollastonite fiber cement paste was $26.4 \%$ higher than that of the pure cement paste after curing for 1 day. After curing for 28 days, compared with the pure sample, the compressive strengths of cement stone increased by $5.6 \%, 10.3 \%, 17.8 \%$, and $22 \%$ with the addition of $2 \%, 4 \%, 6 \%$, and $8 \%$ wollastonite fiber, respectively. Wollastonite fiber can improve the compressive strength of cement paste and the ability of the cement sheath to resist external load.

Figure 8 shows the flexural strength evaluation results of wollastonite fiber cement samples. It can be observed from the evaluation results that wollastonite fiber can significantly improve the flexural strength of cement paste. With the increase in curing age, the flexural strength of cement stone is increased. When the wollastonite fiber content is $6 \%$, the 


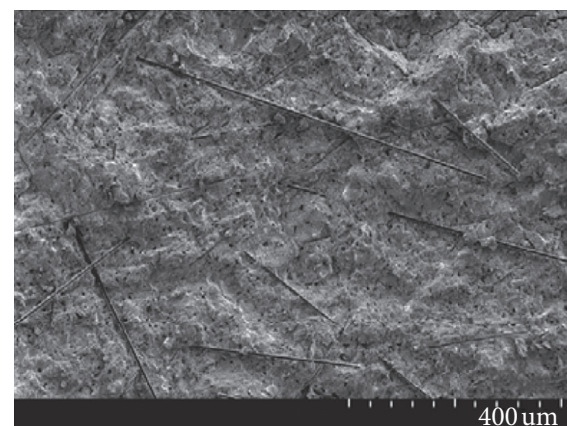

(a)

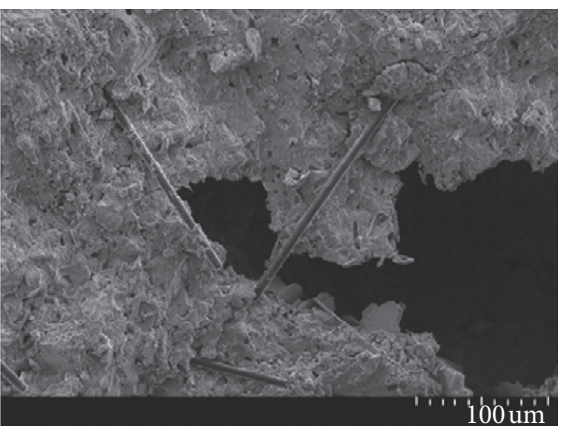

(b)

Figure 2: Fracture morphology of carbon fiber cement sample.

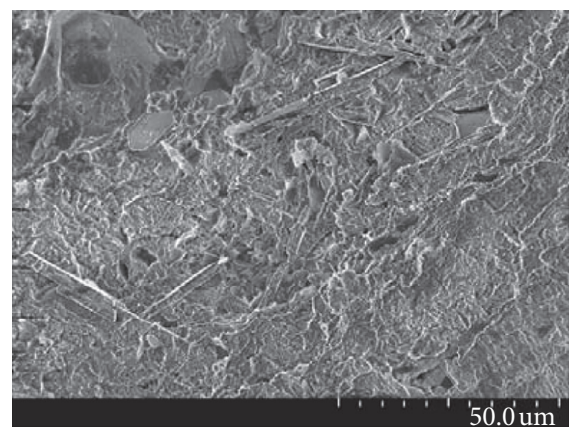

(a)

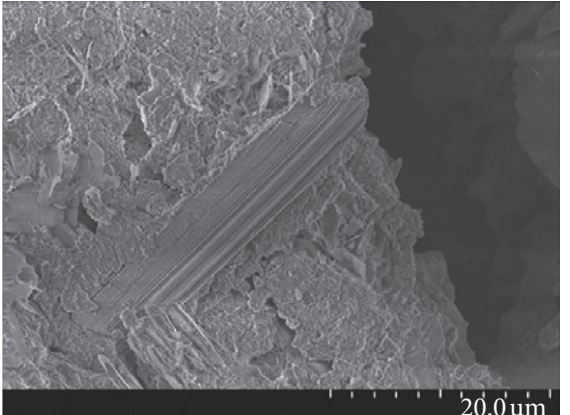

(b)

FIGURE 3: Fracture morphology of wollastonite fiber cement sample.

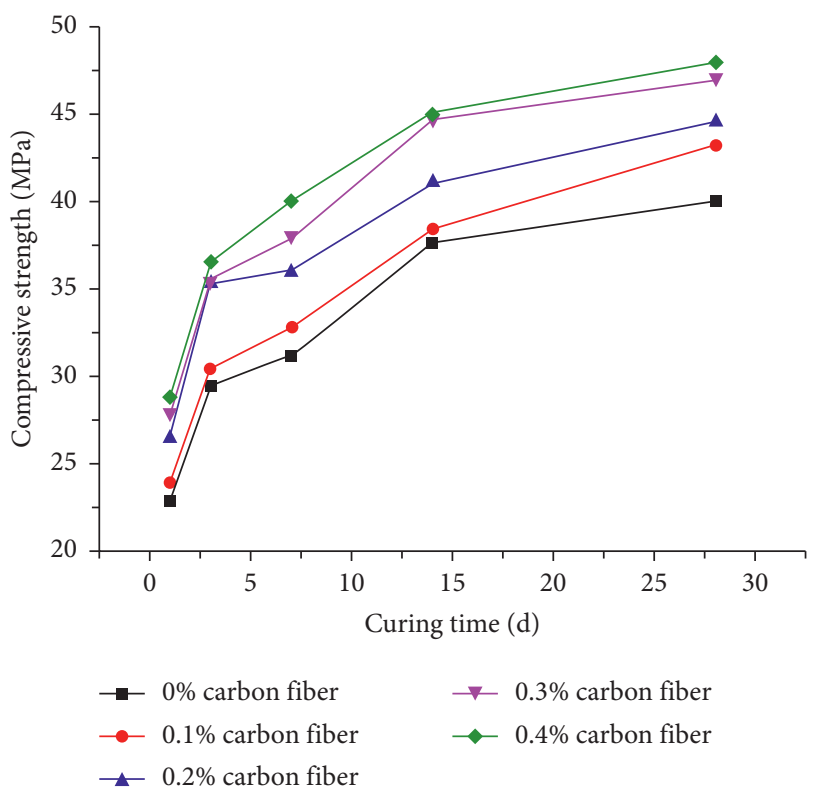

Figure 4: Compressive strength of carbon fiber cement stone.

flexural strength of the cement sample increases most obviously, by approximately $30.2 \%$ and $23.2 \%$ compared with the pure sample after curing for 1 day and 28 days, respectively.

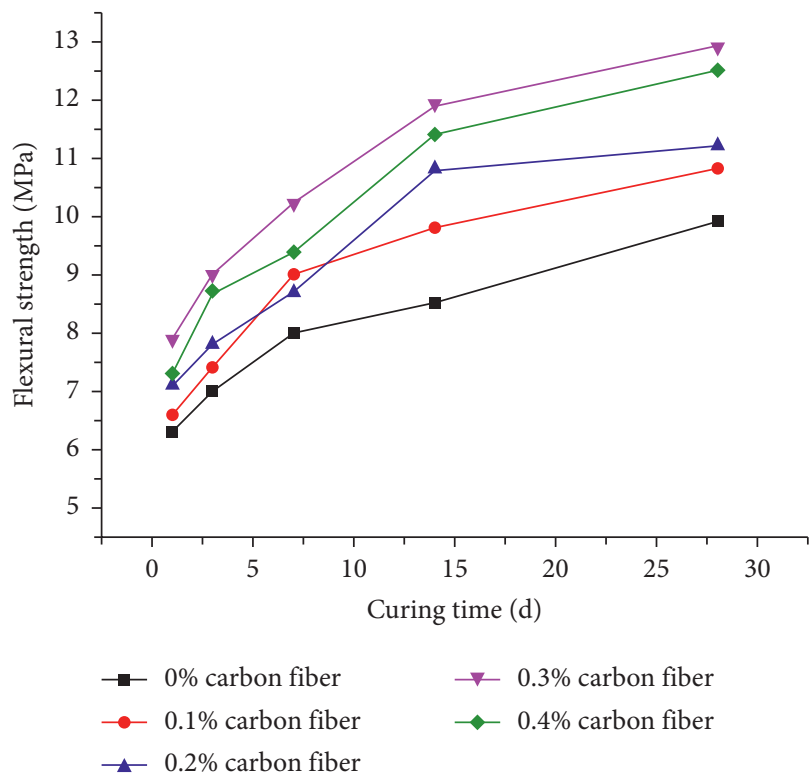

Figure 5: Flexural strength of carbon fiber cement paste.

Figure 9 shows the test results of the impact strength of wollastonite fiber cement stone at different curing ages. Wollastonite fiber can improve the impact strength of the 


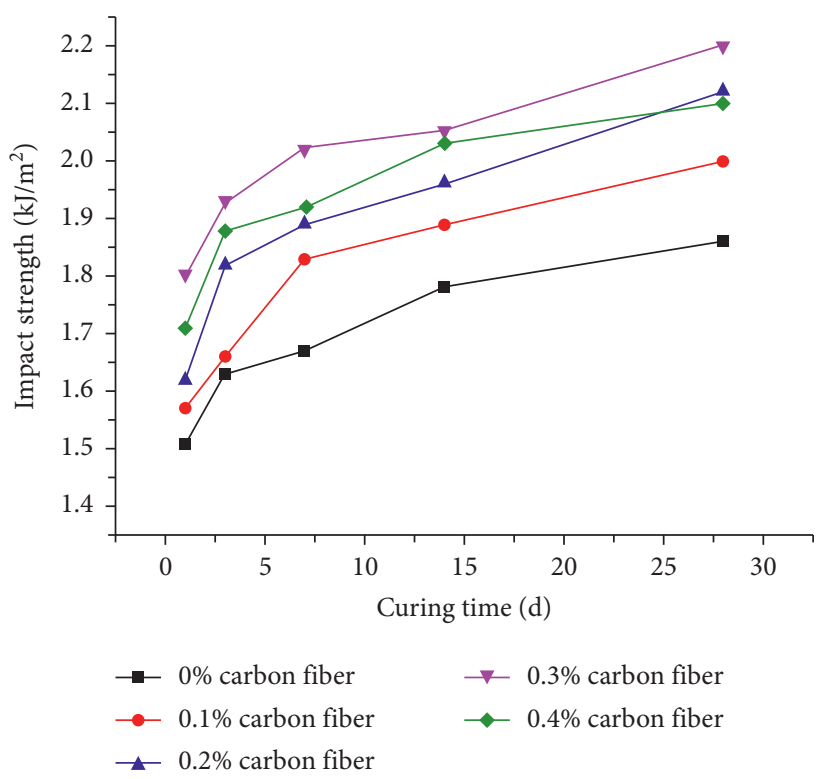

Figure 6: Impact strength of carbon fiber cement stone.

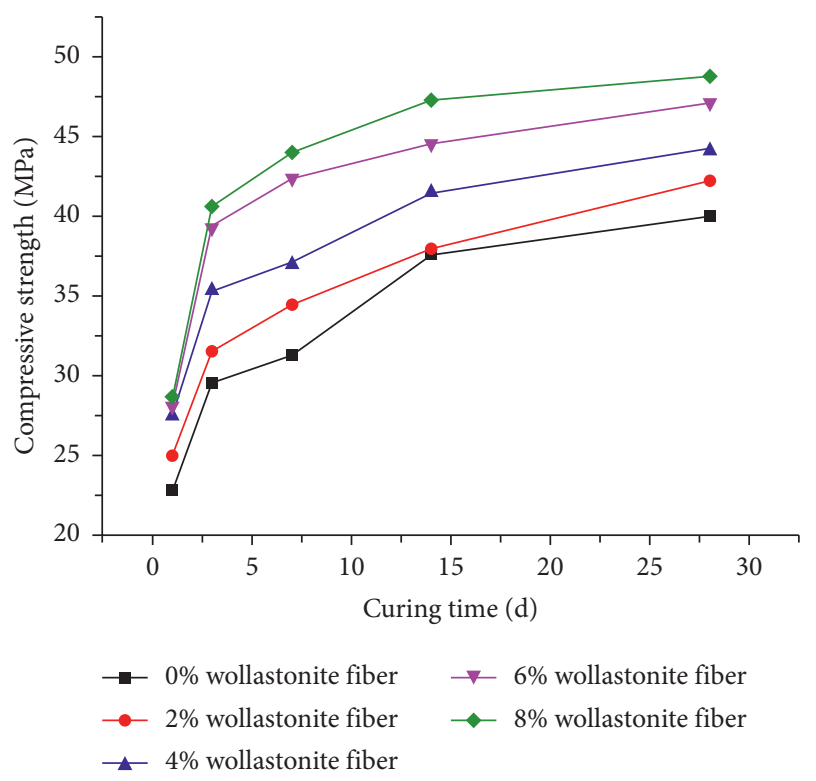

Figure 7: Compressive strength of wollastonite fiber cement stone.

cement stone as well as the conventional fiber. Wollastonite fiber improves the crushing absorption energy of the cement stone. With the extension of curing age, the impact strength of the sample is increased. After curing for one day, the impact strength of the wollastonite fiber cement sample is $17.2 \%$ higher than that of the pure sample. After curing for 28 days, the impact strengths of $2 \%, 4 \%, 6 \%$, and $8 \%$ wollastonite fiber increased by $9.1 \%$, $14 \%, 21.5 \%$, and $12.9 \%$, respectively. The development of the impact strength of the cement sample is the best when the content of wollastonite fiber is $6 \%$, but too much wollastonite fiber is not conducive to the development of the impact strength of the cement.

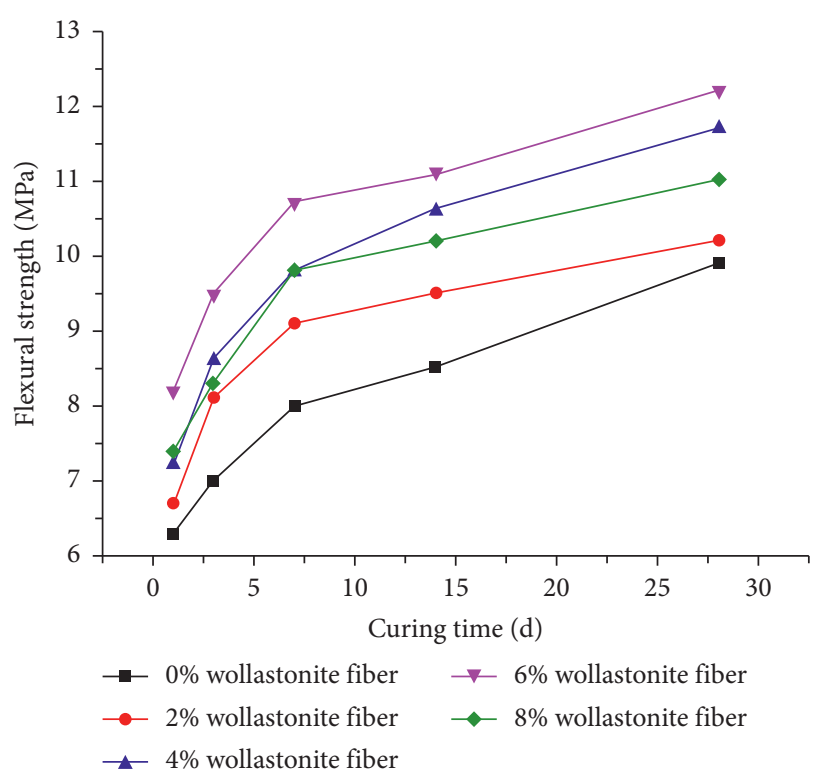

Figure 8: Flexural strength of wollastonite fiber cement stone.

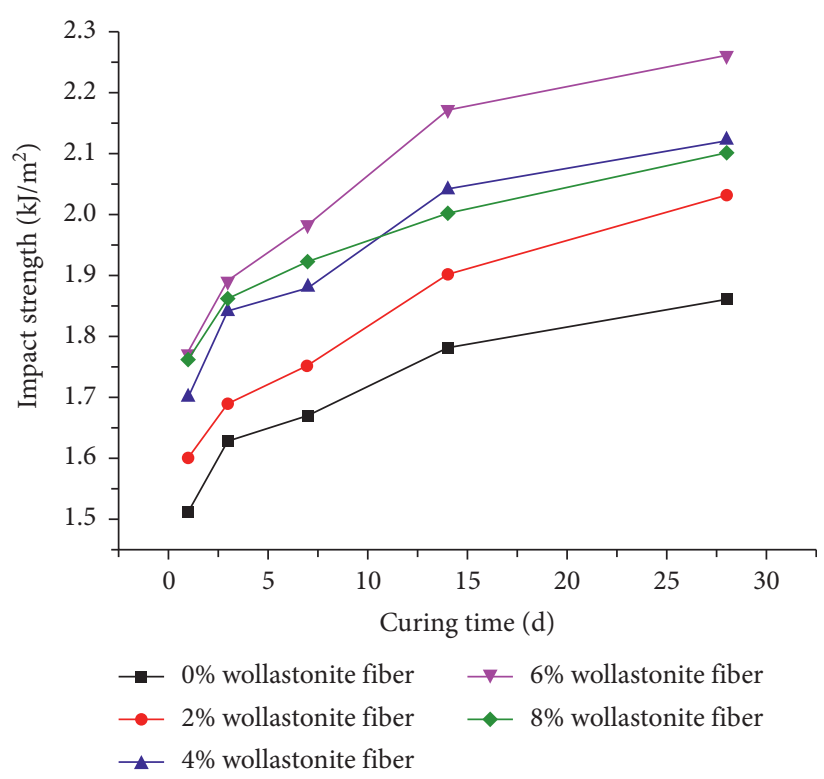

FIgURE 9: Impact strength of wollastonite fiber cement stone.

\subsubsection{Synergistic Effect of Carbon Fiber and Wollastonite} Fiber on the Mechanical Properties of Cement Paste. From the evaluation of the mechanical properties of carbon fiber cement stone and wollastonite fiber cement stone, it was found that when the amount of carbon fiber is greater than $0.3 \%$ or that of wollastonite fiber is greater than $6 \%$, the flexural strength and impact strength of the cement stone might decrease. Therefore, in this experiment, three proportions of hybrid fiber, namely, $0.3 \%$ carbon fiber and $3 \%$ wollastonite fiber (CW1), $0.15 \%$ carbon fiber and $6 \%$ wollastonite fiber (CW2), and $0.3 \%$ carbon fiber and 6\% wollastonite fiber (CW3), were mixed with cement, and the performances of the hybrid fiber cement slurry were evaluated. The performance of the $0.3 \%$ carbon fiber (C3), $6 \%$ 


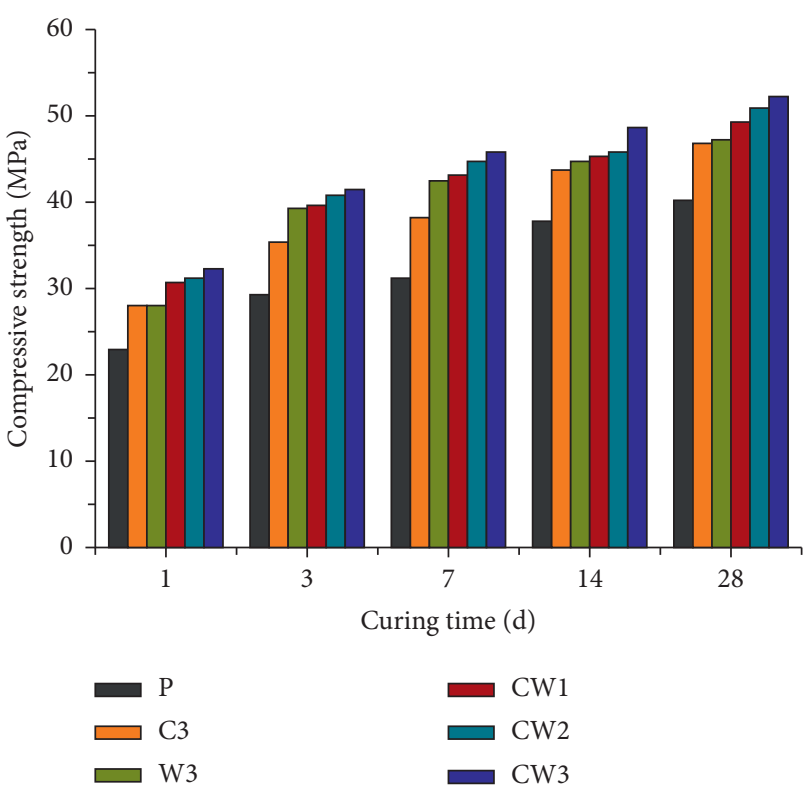

Figure 10: Compressive strength of cement stone mixed with carbon fiber and wollastonite fiber.

wollastonite fiber cement sample (W3), and pure cement stone $(\mathrm{P})$ were compared, and the experimental results are presented in Figures 10-12.

It can be observed from the experimental results that in different curing stages, both fibers can significantly improve the mechanical properties of cement stone, and the compressive strength, flexural strength, and impact strength of the hybrid fiber cement stone are higher than those of single fiber cement stone. Figure 10 shows that the compressive strengths of the three proportions of mixed fiber cement slurry are higher than those of the single fiber cement slurry. When the curing time is $28 \mathrm{~d}$, the compressive strengths of samples CW1, CW2, and CW3 are increased by $23 \%, 26.8 \%$, and $30.8 \%$, respectively, compared with those of the pure cement slurry. The optimal addition amount of single fiber can still greatly improve the effect after mixing. Figure 11 shows a comparison of flexural strength. Fiber contributes substantially to the flexural strength of cement, and hybrid fiber has a better effect. When the curing time is 28 days, the flexural strength of the CW3 sample is $10.4 \%, 13.1 \%$, and $39.4 \%$ higher than that of carbon fiber sample, wollastonite fiber sample, and pure cement, respectively. Figure 12 shows that the impact strength of the mixed fiber cement slurry is higher than that of the single fiber. The impact strengths of the CW1, CW2, and CW3 samples are $24.2 \%, 25.3 \%$, and $29 \%$ higher than those of the pure cement slurry, respectively. The experimental results show that the mixed fiber can improve the cement slurry better than the single fiber, and the optimal additive combination of fibers can also achieve better performance.

3.3. Stress-Strain Behavior of Cement Paste. Figure 13 presents the stress-strain behavior of pure cement stone $(\mathrm{P})$, carbon fiber

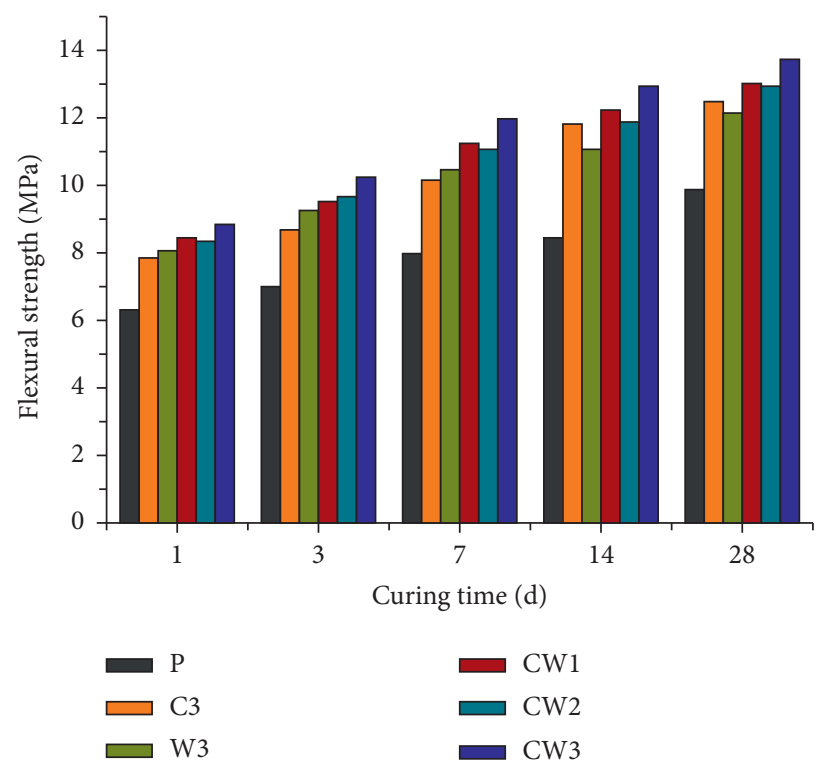

FIGURE 11: Flexural strength of cement stone mixed with carbon fiber and wollastonite fiber.

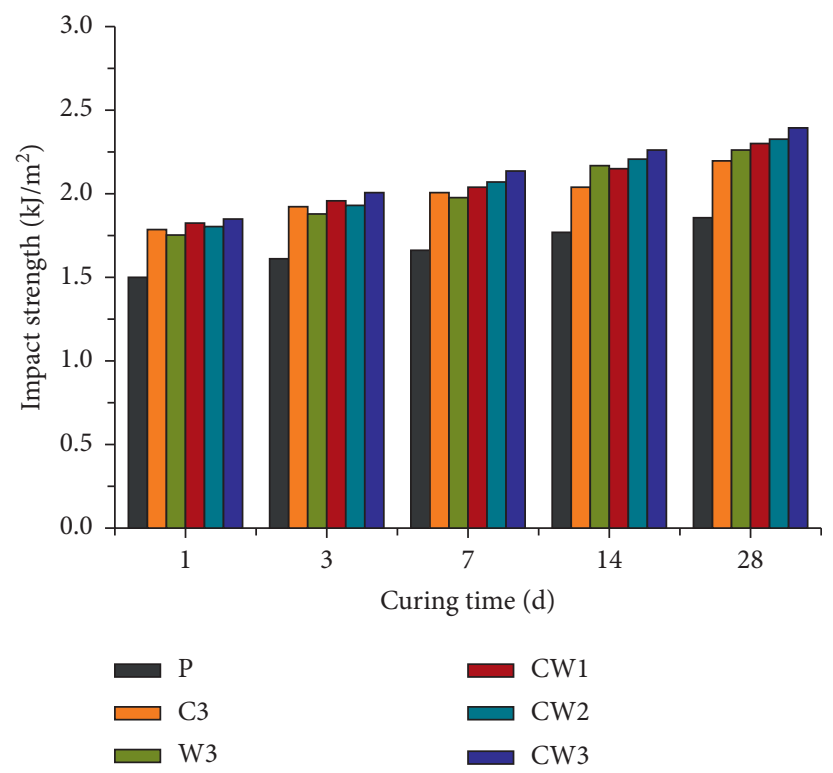

FIGURE 12: Impact strength of cement stone mixed with carbon fiber and wollastonite fiber.

cement stone (C3), wollastonite fiber cement stone (W3), and cement stone mixed with two fibers (CW) under a compression load. It can be observed from the stress-strain curve that the stress-strain curve of pure cement paste is approximately a straight line. When the pure cement is subjected to stress compression, it displays brittleness, and when it reaches the maximum stress, the cement is rapidly destroyed. When the cement stone with fiber material is compressed, a straight line appears at first. With continuous loading, a nonlinear curve appears, and creep occurs continuously, showing elastic deformation ability $[24,25]$. The stress of the cement paste is increased and the strain of the cement paste is also increased by 


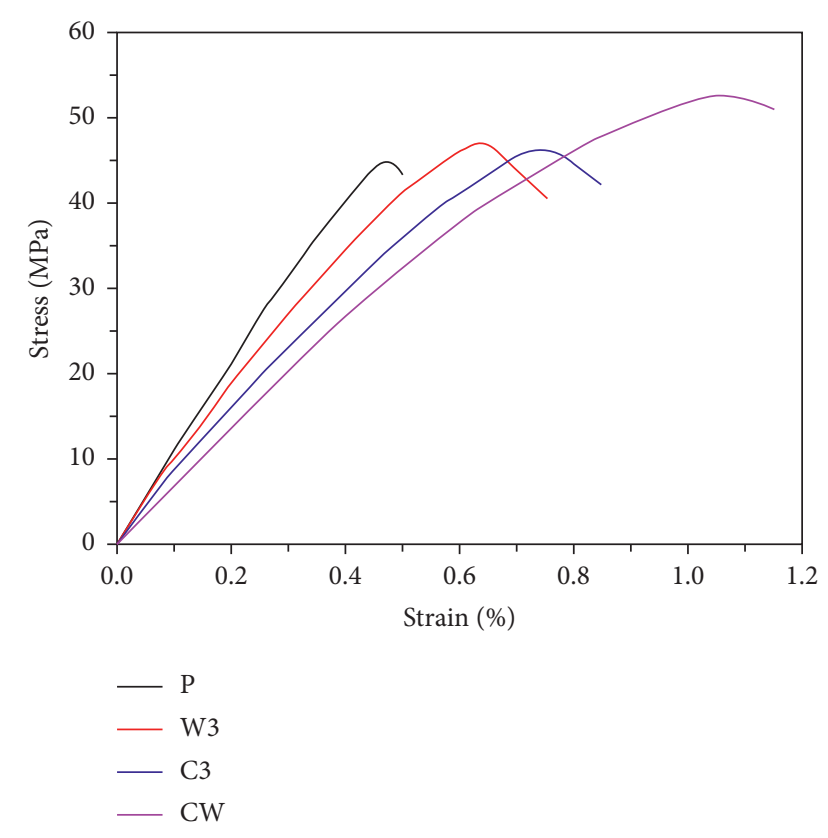

FIGURE 13: Stress-strain curve of fiber cement paste.

the single fiber. Under the same stress condition, the strain of cement stone is the largest when the two fibers are mixed, followed by that of the carbon fiber cement stone. The deformation ability of fiber cement is strong, and the use of mixed materials can improve the load resistance of cement. The elastic model of cement paste can be calculated from the stress-strain curve. The experimental results demonstrate that the strain of blank cement is $0.4 \%$, and the elastic modulus is $9.8 \mathrm{GPa}$. Compared with the pure cement stone, the strain of the mixed cement stone increases substantially, and the elastic modulus decreases by $37.8 \%$. The experimental results show that the hybrid effect of carbon fiber and wollastonite fiber can improve the deformation ability and elasticity of cement paste.

\section{Conclusion}

(1) Carbon fiber and wollastonite fiber are scattered in the cement slurry, and the mechanical properties of the cement paste are improved by bridging and pulling out behaviors.

(2) Single carbon fiber or wollastonite fiber can improve the compressive strength, flexural strength, and impact strength of cement paste, but too many fibers are not conducive to the development of flexural strength and impact strength of cement paste.

(3) The mechanical properties of cement stone can be enhanced by mixing two types of fibers. The flexural strength, compressive strength, and impact strength of hybrid fiber cement stone are higher than those of single fiber cement stone.

(4) The stress-strain behavior shows that the hybrid fiber cement stone has the highest stress and the largest strain. The elastic modulus decreases substantially, and the deformation ability of the cement stone increases greatly.

\section{Data Availability}

The data used to support the findings of this study are included within the article.

\section{Conflicts of Interest}

The authors declare that they have no conflicts of interest regarding the publication of this paper.

\section{Acknowledgments}

This work was supported by the National Science and Technology Major Project (no. 2016ZX05026-002) funded by the Chinese Government.

\section{References}

[1] N. Jafariesfad, M. R. Geiker, Y. Gong, P. Skalle, Z. Zhang, and J. He, "Cement sheath modification using nanomaterials for long-term zonal isolation of oil wells: Review," Journal of Petroleum Science and Engineering, vol. 156, pp. 662-672, 2017.

[2] J. Song, M. Xu, W. Liu, X. Wang, and Y. Wu, "Synergistic effect of latex powder and rubber on the properties of oil well cement-based composites," Advances in Materials Science and Engineering, vol. 2018, Article ID 4843816, 9 pages, 2018.

[3] A. Ahmed, S. Elkatatny, R. Gajbhiye et al., "Effect of polypropylene fibers on oil-well cement properties at HPHT condition," in Proceedings of the SPE Kingdom of Saudi Arabia Annual Technical Symposium and Exhibition, Dammam, Saudi Arabia, April 2018.

[4] S. S. Iremonger, M. Bolt, and S. C. Lawrence, "Enhanced thermal well integrity through the use of a new cement tensile strength-enhancing fiber," in Proceedings of the SPE Canada Heavy Oil Technical Conference, Calgary, Canada, June 2015.

[5] K. Liu, X. Cheng, X. Zhang, X. Guo, and J. Zhuang, "Design of low-density cement optimized by cellulose-based fibre for oil and natural gas wells," Powder Technology, vol. 338, pp. 506-518, 2018.

[6] Y. H. Bu, R. H. Wang, and R. C. Cheng, "Performance of fiber cement slurry for well cementation," Oil Drilling and Production Technology, vol. 27, no. 2, pp. 25-27, 2005.

[7] M. Li, Y. J. Yang, and X. Y. Guo, "Mechanical properties of carbon fiber reinforced oil well cement composites," Fuhe Cailiao Xuebao/Acta Materiae Compositae Sinica, vol. 32, no. 3, pp. 782-788, 2015.

[8] M. Li, Y. J. Yang, J. Z. Jin et al., "Reinforced mechanical properties and mechanism of well-cementing stones by brucite fiber," Natural Gas Industry, vol. 35, no. 6, pp. 82-86, 2015.

[9] X. K. Li and J. Zhuang, "Performance research of brucite fibers reinforced oil well cement paste," Oilfield Chemistry, vol. 32, no. 2, pp. 169-174, 2015.

[10] L. C. M. Paiva, I. M. Ferreira, A. E. Martinelli, J. C. d. O. Freitas, and U. T. Bezerra, "Milled basalt fiber reinforced Portland slurries for oil well applications," Journal of Petroleum Science and Engineering, vol. 175, pp. 184-189, 2019. 
[11] C. Jiang, K. Fan, F. Wu, and D. Chen, "Experimental study on the mechanical properties and microstructure of chopped basalt fibre reinforced concrete," Materials \& Design, vol. 58, no. 6, pp. 187-193, 2014.

[12] D. A. S. Rambo, F. D. A. Silva, R. D. T. Filho et al., "Tensile strength of a calcium-aluminate cementitious composite reinforced with basalt textile in a high-temperature environment," Cement \& Concrete Composites, vol. 70, pp. 183$193,2016$.

[13] S. Kurata and K. Umemoto, "Study on the mechanical properties of polycarboxylate cement containing aluminoborate whisker," Journal of the Japanese Society for Dental Materials \& Devices, vol. 25, pp. 246-250, 2006.

[14] M. Li, Y. Yang, M. Liu, X. Guo, and S. Zhou, "Hybrid effect of calcium carbonate whisker and carbon fiber on the mechanical properties and microstructure of oil well cement," Construction and Building Materials, vol. 93, no. 1, pp. 9951002, 2015.

[15] V. J. Ferrari, J. B. de Hanai, and R. A. de Souza, "Flexural strengthening of reinforcement concrete beams using high performance fiber reinforcement cement-based composite (HPFRCC) and carbon fiber reinforced polymers (CFRP)," Construction and Building Materials, vol. 48, no. 19, pp. 485-498, 2013.

[16] Y. Xu and D. D. L. Chung, "Silane-treated carbon fiber for reinforcing cement," Carbon, vol. 39, no. 13, pp. 1995-2001, 2001.

[17] S. Chakraborty, S. P. Kundu, A. Roy, B. Adhikari, and S. B. Majumder, "Effect of jute as fiber reinforcement controlling the hydration characteristics of cement matrix," Industrial \& Engineering Chemistry Research, vol. 52, no. 3, pp. 1252-1260, 2013.

[18] W. T. Lin, R. Huang, C. L. Lee et al., "Effect of steel fiber on the mechanical properties of cement-based composites containing silica fume," Journal of Marine Science \& Technology, vol. 16, no. 3, pp. 214-221, 2008.

[19] A. Peled, J. Jones, and S. P. Shah, "Effect of matrix modification on durability of glass fiber reinforced cement composites," Materials and Structures, vol. 38, no. 2, pp. 163-171, 2005.

[20] E. M. Bezerra, A. P. Joaquim, H. Savastano Jr., V. M. John, and V. Agopyan, "The effect of different mineral additions and synthetic fiber contents on properties of cement based composites," Cement and Concrete Composites, vol. 28, no. 6, pp. 555-563, 2006.

[21] J. Song, M. Xu, W. Liu et al., "Thermoplastic rubber (TPR) modified by a silane coupling agent and its influence on the mechanical properties of oil well cement pastes," Advances in Materials Science and Engineering, vol. 2019, Article ID 3587081, 11 pages, 2019.

[22] P. Jamsawang, P. Voottipruex, and S. Horpibulsuk, "Flexural strength characteristics of compacted cement-polypropylene fiber sand," Journal of Materials in Civil Engineering, vol. 27, no. 9, Article ID 04014243, 2014.

[23] V. Bindiganavile, N. Banthia, and B. Aarup, "Impact response of ultra-high-strength fiber-reinforced cement composite," ACI Materials Journal, vol. 99, no. 6, pp. 543-548, 2002.

[24] A. Noushini, F. Aslani, A. Castel, R. I. Gilbert, B. Uy, and S. Foster, "Compressive stress-strain model for low-calcium fly ash-based geopolymer and heat-cured Portland cement concrete," Cement and Concrete Composites, vol. 73, pp. 136-146, 2016.

[25] S. B. Zhao, M. S. Zhao, X. Y. Zhang et al., "Study on complete stress-strain curves of steel fiber reinforced lightweight aggregate concrete under uniaxial compression," Journal of Building Structures, vol. 40, no. 5, pp. 181-190, 2019. 